\title{
Estrutura genética de populações de pindaíba (Xylopia brasiliensis Sprengel) por isoenzimas ${ }^{1}$
}

\author{
SHEILA ISABEL DO CARMO PINTO² e DULCINÉIA DE CARVALHO ${ }^{2,3}$
}

(recebido: 28 de maio de 2003; aceito: 17 de junho de 2004)

\begin{abstract}
Genetic structure in populations of pindaíba (Xylopia brasiliensis Sprengel) by isozymes). Two populations of Xylopia brasiliensis Sprengel were studied by isozymes electrophoresis in order to establish the variability levels maintained between and within populations, the genetic structure, the gene flow and the effective size of the populations. The samplings were done at the "Reserva Florestal da UFLA" (Population 1) and in the understorey of experimental planting of Eucalyptus spp (Population 2) located in Lavras region, south of Minas Gerais State. Leaf tissues from 20 adult plants (Population 1) and 20 seedlings and 20 young plants (Population 2) were collected. The studies in the two populations by seven enzymatic systems revealed 36 alleles distributed in 16 loci. The proportion of polymorphic loci $(P)(0.95)$ was $68.8 \%$ for the Population 1 and $87.5 \%$ for the Population 2. The average number of alleles per locus (A) was 1.9 to 2.2 and the genetic diversity measured by average heterozygosity expected $\left(\hat{H}_{e}\right)$ was 0.313 to 0.424 . The genetic structure revealed an excess of heterozygotes for both populations $(\hat{F}=-0.221)$. The populations presented genetic divergence of $\hat{\theta}_{p}=0.092$. The gene flow evaluated by the number of migrants was low $\hat{N}_{m}=0.50$. The minimum area size estimated for the in situ conservation of $X$. brasiliensis was 10.08 ha.
\end{abstract}

Key words - genetic structure, isozymes, Xylopia brasiliensis

RESUMO - (Estrutura genética de populações de pindaíba (Xylopia brasiliensis Sprengel) por isoenzimas). Duas populações de Xylopia brasiliensis Sprengel foram estudadas por meio da eletroforese de isoenzimas, visando determinar os níveis de variabilidade genética mantidos entre e dentro das populações, sua estrutura genética, o fluxo gênico e o tamanho efetivo populacional. As amostragens foram efetuadas na "Reserva Florestal da UFLA" (População 1) e no sub-bosque de um plantio experimental com várias espécies de eucalipto (População 2) na região de Lavras, sul do Estado de Minas Gerais. Na População 1 coletou-se tecido foliar de 20 indivíduos reprodutivos e na População 2 foram coletados 20 plântulas e 20 indivíduos jovens. A análise das duas populações por meio de sete sistemas enzimáticos revelou a presença de 36 alelos totais distribuídos em 16 locos. O polimorfismo ( $P$ ) com limite de freqüência igual ou inferior a 0,95 foi de $68,8 \%$ para a População 1 e de $87,5 \%$ para a População 2. O número médio de alelos por loco (A) variou de 1,9 a 2,2 e a diversidade genética medida pela heterozigosidade média esperada $\left(\hat{H}_{e}\right)$ variou de 0,313 a 0,424 . A estrutura genética revelou que há uma tendência de excesso de heterozigotos para o conjunto das populações $(\hat{F}=-0,221)$. As populações apresentaram divergência genética de $\hat{\theta_{p}}=0,092$. O fluxo gênico medido pelo número de migrantes foi baixo $\hat{N}_{m}=0,50$. A área mínima estimada para a conservação in situ de uma população de X. brasiliensis foi de 10,08 ha.

Palavras-chave - estrutura genética, isoenzimas, Xylopia brasiliensis

\section{Introdução}

No Brasil, como em outros países tropicais, uma exploração puramente predatória vem sendo adotada para as florestas nativas em virtude da explosão demográfica e expansão das fronteiras agrícolas. Este tipo de exploração, aliado ao desconhecimento das exigências culturais, da biologia reprodutiva, da regeneração e do padrão de distribuição genética das diferentes espécies florestais nativas, tem ocasionado deterioração da base genética, comprometendo o patrimônio genético dos ecossistemas.

Parte da monografia da primeira autora.

2. Universidade Federal de Lavras, Departamento de Ciências Florestais, Caixa Postal 37, 37200-000 Lavras MG, Brasil.
Além da exploração predatória, a perda e a fragmentação dos hábitats podem acarretar a extinção de populações locais. A fragmentação dos hábitats pode levar a perdas da biodiversidade e mudanças na distribuição e abundância das espécies devido à descontinuidade da vegetação original, acarretando impedimentos para a migração, restrição do tamanho das populações e acréscimo dos efeitos de borda.

Diante de tal realidade, são imprescindíveis estudos genéticos em nível populacional das espécies que compõem tais ecossistemas, para que sejam estabelecidas estratégias de conservação genética sobretudo em áreas perturbadas, procurando reunir subsídios que contribuam para a conservação in situ, o manejo sustentado e a formação de áreas de coletas de sementes visando à recuperação de áreas degradadas. 
Os marcadores bioquímicos como as isoenzimas complementam os métodos tradicionalmente empregados no melhoramento, no manejo e na conservação de espécies florestais (Robinson 1998). Inúmeras investigações têm utilizado esta técnica para estimar os níveis de variabilidade genética de populações naturais, estudar o fluxo gênico entre populações, a dispersão de espécies, tamanho efetivo da população e taxas de cruzamento (Ferreira \& Grattapaglia 1998, Lepsch-Cunha et al. 1999). No Brasil, várias pesquisas utilizando marcadores isoenzimáticos foram realizadas com espécies arbóreas nativas (Lepsch-Cunha et al. 1999, Oliveira et al. 2002, Sebben et al. 2003).

A espécie Xylopia brasiliensis Sprengel (Annonaceae), com distribuição natural desde o sul do Estado da Bahia até o Estado do Rio Grande do Sul, na floresta pluvial da encosta atlântica, é uma espécie perenifólia, heliófita, ocorrendo preferencialmente com bastante frequiência ao longo das encostas enxutas, tanto da mata primária densa como nas formações abertas e secundárias (Lorenzi 1992). A pindaíba apresenta dispersão ornitocórica e o sistema de cruzamento é predominantemente alógamo com pequena produção de frutos por autogamia. Segundo Lorenzi (1992), os frutos da pindaíba são muito apreciados por pássaros. Além disso, apresenta rápido crescimento sendo útil em reflorestamentos heterogêneos destinados à recomposição de áreas degradadas de preservação permanente.

Portanto, é importante, tanto para os programas de conservação genética como para o manejo florestal, conhecer o modo como a variabilidade genética está partilhada dentro e entre populações, o fluxo gênico, a endogamia e o tamanho efetivo populacional. A realização deste trabalho visa contribuir para a ampliação dos conhecimentos sobre a espécie X. brasiliensis Sprengel, em especial para a caracterização da variabilidade genética entre e dentro das populações, visando a adoção de estratégias de manejo, conservação genética e restauração de áreas.

\section{Material e métodos}

Locais de estudo - O estudo foi realizado na Reserva Florestal da UFLA na cidade de Lavras, sul do estado de Minas Gerais, onde se coletou tecido foliar de indivíduos reprodutivos (População 1) e em sub-bosque de um plantio experimental com várias espécies de eucalipto adjacente à Reserva Florestal (População 2), onde se efetuou a coleta de regenerantes da espécie $X$. brasiliensis observando a subdivisão em dois estratos diferentes.
A Reserva Florestal da UFLA é um fragmento florestal com área de 5,8 ha, localizado no campus da Universidade Federal de Lavras (UFLA). Sua vegetação é classificada como Floresta Estacional Semidecidual Montana e está localizada nas coordenadas $21^{\circ} 14^{\prime} 42^{\prime \prime} \mathrm{S}$ e $44^{\circ} 57^{\prime} 47^{\prime \prime} \mathrm{W}$, em uma altitude média de $925 \mathrm{~m}$. O tipo climático é Cwb na classificação de Köppen, com temperatura média de $19,3{ }^{\circ} \mathrm{C}$ e precipitação anual média de 1493,2 mm. Os solos são do tipo Latossolo Roxo distrófico (epiálico), textura muito argilosa e relevo suave ondulado (Curi et al. 1990).

A segunda área de estudo refere-se a um plantio experimental com diversas espécies de eucalipto, com cerca de 27 anos de idade, instalado com o objetivo de testar a adaptação de diferentes espécies de eucalipto à região de Lavras. Atualmente, encontra-se uma ampla regeneração de indivíduos da espécie $X$. brasiliensis no sub-bosque, o que propiciou a coleta destes para o estudo da diversidade genética da espécie.

Amostragem dos indivíduos e procedimentos de eletroforese de isoenzimas - A amostragem dos indivíduos na Reserva Florestal (População 1) foi aleatória procurando abranger toda área. Foram efetuadas coletas de tecido foliar de 20 indivíduos reprodutivos. A amostragem dos regenerantes no sub-bosque do plantio de eucalipto foi efetuada em dois estratos. O estrato 1 refere-se a "indivíduos jovens" com diâmetro variando entre 3 e $10 \mathrm{~cm}$ e o estrato 2 refere-se a "plântulas" com diâmetro máximo de $1 \mathrm{~cm}$. A amostragem foi efetuada em toda a área do plantio, coletando-se tecido foliar de 20 indivíduos em cada estrato. Portanto, a estrutura genética da população foi estudada com amostras de 60 indivíduos. Não foi possível estudar a estrutura de progênies, pois a espécie apresenta baixa taxa de germinação (Lorenzi 1992). As amostras foram acondicionadas em sacos plásticos identificados, colocadas em caixa de isopor com gelo, transportadas para o Laboratório de Melhoramento Florestal e Recursos Genéticos (DCFUFLA) e armazenadas em freezer a $-76{ }^{\circ} \mathrm{C}$ para posterior extração das enzimas com $1 \mathrm{~mL}$ de solução tampão de extração $\mathrm{n}^{\circ} 1$ de Alfenas et al. (1998). A eletroforese utilizada foi a vertical, conduzida em meio suporte de gel de poliacrilamida, com gel de concentração a 4,0\% e de separação a $12,5 \%$. Para a corrida eletroforética utilizou-se amperagem de $10 \mathrm{~mA}$ por gel com tempo médio de corrida de $3 \mathrm{~h}$ e $30 \mathrm{~min}$, sob temperatura de $4{ }^{\circ} \mathrm{C}$. Ao término da corrida, as placas foram retiradas da cuba e os géis removidos das placas de vidro e submetidos à coloração de enzimas específicas até o aparecimento das bandas (tabela 1), segundo protocolos já estabelecidos por Brune et al. (1998). Após o surgimento das bandas, os géis foram retirados da solução de revelação, lavados em água corrente e fixados em solução aquosa de glicerol a $10 \%$. A secagem dos géis foi efetuada em secador de gel automático (modelo 583, BioRad).

Interpretação dos zimogramas - As interpretações foram feitas logo após a revelação para os diferentes sistemas enzimáticos. A identificação das zonas codificadoras dos locos e dos alelos foi feita a partir da região mais catódica 
Tabela 1. Sistemas enzimáticos testados para Xylopia brasiliensis Sprengel.

Table 1. Enzymatic systems tested for Xylopia brasiliensis Sprengel.

\begin{tabular}{|c|c|c|}
\hline Enzima & Sigla & $\begin{array}{l}\text { Referência } \\
\text { (E.C) }\end{array}$ \\
\hline Álcool Desidrogenase & $\mathrm{ADH}$ & EC 1.1.1.1 \\
\hline Alfa-Esterase & $\alpha$-EST & EC 3.1.1.1 \\
\hline Beta-Esterase & $\beta$-Est & EC 3.1.1.1 \\
\hline Beta-Galactose Desidrogenase & $\beta-G L D H$ & EC 1.1.1.48 \\
\hline Catalase & CAT & EC 1.11.1.6 \\
\hline Enzima Málica & $\mathrm{ME}$ & EC 1.1.1.40 \\
\hline Fosfatase Ácida & $\mathrm{ACP}$ & EC 3.1.3.2 \\
\hline Fosfatase Alcalina & ALP & EC 3.1.3.1 \\
\hline Fosfoglucomutase & PGM & EC 2.7.5.1 \\
\hline 6-Fosfogluconato Desidrogenase & 6PGDH & EC 1.1.1.44 \\
\hline Fosfoglucose Isomerase & PGI & EC 5.3.1.9 \\
\hline Glucose Desidrogenase & GLUDH & EC 1.1.1.47 \\
\hline Glucose-6-Fosfato Desidrogenase & G6PDH & EC 1.1.1.49 \\
\hline Glutamato Desidrogenase & GTDH & EC 1.4.1.3 \\
\hline Glutamato-Oxaloacetato Transaminase & GOT & EC 2.6.1.1 \\
\hline Isocitrato Desidrogenase & IDH & EC 1.1.1.42 \\
\hline Leucina Aminopeptidase & LAP & EC 3.4.11.1 \\
\hline Malato Desidrogenase & $\mathrm{MDH}$ & EC 1.1.1.37 \\
\hline Peroxidase & $\mathrm{PO}$ & EC 1.11.1.7 \\
\hline Sorbitol Desidrogenase & $\mathrm{SDH}$ & EC 1.1.1.14 \\
\hline Superóxido Dismutase & SOD & EC 1.15.1.1 \\
\hline
\end{tabular}

$\mathrm{EC}=$ Enzyme Commission

para a mais anódica. A interpretação de cada sistema enzimático foi realizada seguindo os padrões descritos em trabalhos utilizando sistemas enzimáticos (Weeden 1983, Soltis \& Soltis 1989, Kephart 1990, Alfenas et al. 1991).

Análises estatísticas - A interpretação dos zimogramas permitiu a determinação dos genótipos de cada indivíduo, possibilitando estimar vários parâmetros que caracterizam a variabilidade genética entre e dentro das populações, a sua estrutura genética, o fluxo gênico e o tamanho efetivo das populações. As freqüências alélicas descrevem a variação para um loco e foram estimadas pela contagem direta do número de alelos por loco, dividido pelo número total de alelos no loco: $\hat{P}_{i}=\mathrm{n}_{\mathrm{i}} / \mathrm{n}$, sendo $\hat{P}_{i}$ a freqüência do alelo i, $\mathrm{n}_{\mathrm{i}} \mathrm{o}$ número de ocorrência do alelo i e n o número total de alelos amostrados. A partir das frequiências alélicas foram estimados os índices de diversidade genética, tais como: heterozigosidade média observada $\left(\hat{H}_{o}\right)$; heterozigosidade média esperada $\left(\hat{H}_{e}\right)$; número médio de alelos por loco (A); porcentagem de locos polimórficos (P) e índices de fixação de Wright ( $\hat{f}$ ), estimativas obtidas a partir do programa BIOSYS-2, desenvolvido por Swofford \& Selander (1989).
A estrutura genética foi abordada a partir dos coeficientes de coancestralidade de Cockerham (Cockerham 1969, Vencovsky 1992), obtidos a partir da decomposição dos componentes de variação da análise de variância das freqüências alélicas, conforme Cockerham (1969). A análise de variância foi realizada com a utilização do programa GDA (Lewis \& Zaykin 2000).

As estimativas do fluxo gênico entre as populações foram obtidas segundo a equação proposta por Crow \& Aoki (1984): $\hat{N}_{m}=[(1 / \hat{F} \mathrm{st})-1] / 4 \alpha$, onde: $\alpha=[\mathrm{n} /(\mathrm{n}-1)]^{2}$, sendo $\hat{N}_{m}$ o número de migrantes e $\mathrm{n}$ o número de populações. $\mathrm{O}$ tamanho da vizinhança foi estimado por $\hat{N}_{b}=2 \mathrm{p} \hat{N}_{m}$.

\section{Resultados e Discussão}

Sistemas enzimáticos - Durante a realização deste estudo vários sistemas enzimáticos foram testados (tabela 1), visando o estabelecimento de um protocolo para a espécie Xylopia brasiliensis. Dentre estes, apenas sete sistemas foram adotados para as análises por apresentar locos passíveis de interpretação.

As características apresentadas em cada sistema enzimático para os tecidos foliares de $X$. brasiliensis Sprengel foram:

Beta Esterase ( $\beta$-EST) - Este sistema enzimático apresentou três locos polimórficos compostos por dois alelos para as duas populações.

Fosfatase Ácida (ACP) - Este sistema enzimático revelou dois locos. O loco 1 apresentou-se polimórfico com três alelos para as duas populações. O loco 2 apresentou-se monomórfico com a fixação do alelo 3 para a População1 e polimórfico para os jovens e plântulas, sendo composto por dois e três alelos, respectivamente (População 2).

Fosfogluco Isomerase (PGI) - Este sistema enzimático revelou apenas um loco, que se apresentou polimórfico, sendo composto por três alelos nos adultos e por dois alelos nos jovens e plântulas.

Glutamato Desidrogenase (GTDH) - Este sistema enzimático apresentou dois locos polimórficos compostos por dois alelos para as duas populações.

Glutamato Oxaloacetato Transaminase (GOT) - Este sistema enzimático apresentou dois locos monomórficos com fixação do alelo 1 para as duas populações estudadas.

Malato Desidrogenase (MDH) - Este sistema enzimático apresentou três locos. O primeiro apresentou-se polimórfico com dois alelos nas plântulas e monomórfico com fixação do alelo 1 nos demais. Os locos 2 e 3 apresentaram-se polimórficos, sendo compostos por dois alelos.

Peroxidase (PO) - Este sistema enzimático apresentou 
três locos, sendo o primeiro monomórfico com a fixação do alelo 1 para a População 1 e polimórfico com três alelos para os indivíduos jovens e plântulas (População 2). O segundo loco apresentou-se polimórfico com três alelos para as duas populações. $\mathrm{O}$ terceiro loco apresentou-se polimórfico para as duas populações, sendo composto por três alelos nos indivíduos jovens e plântulas e por dois alelos nos adultos da População 1.

Frequiências alélicas - Com o objetivo de estimar os índices de diversidade genética e os parâmetros quantificadores da estrutura genética das populações de $X$. brasiliensis foram obtidas as frequiências alélicas de 36 alelos distribuídos em 16 locos aloenzimáticos (tabela 2).

Na População 1, dos 16 locos analisados, cinco apresentaram-se monomórficos: Got-1, Got-2, Po-1, Acp-2 e Mdh-1; no estrato de indivíduos jovens, três locos apresentaram-se monomórficos: Got-1, Got-2 e Mdh-1 e no estrato de plântulas apenas os locos Got-1 e Got-2 apresentaram-se monomórficos.

As freqüências alélicas variaram nas duas populações desde uma fixação de alelos dos locos Got-1, Got-2, Po-1, Acp-2 e Mdh-1 (adultos), Got-1, Got-2, e Mdh-1 (jovens) e Got-1 e Got-2 (plântulas) até frequiências muito baixas, como no caso do alelo 1 no loco Po-2 $(0,059)$, alelo 3 no loco Po-3 $(0,075)$ e alelo 1 no loco Pgi-1 $(0,075)$, nos adultos; alelo $2(0,025)$ e alelo $3(0,075)$ no loco Po-3 e alelo 2 no loco Gtdh-2 $(0,071)$, nos indivíduos jovens; alelo 2 no loco Po-3 $(0,025)$ nas plântulas.

A presença de alguns alelos foi exclusiva em indivíduos dos estratos estudados, tais como: alelo 1 no loco Pgi-1 (adultos); alelos 2 e 3 no loco Po-1, alelo 2 no loco Po-3 e alelo 2 no loco Acp-2 (jovens e plântulas); alelo 1 no loco Acp-2 e alelo 2 no loco Mdh-1 (plântulas).

Os dados dos 16 locos aloenzimáticos demonstraram que as freqüências alélicas variaram tanto entre quanto dentro das duas populações estudadas, sobretudo quando se verifica a presença de alelos raros ausentes nos indivíduos adultos. Este fato pode ter ocorrido devido a dois fatores: a) variação amostral natural nos indivíduos adultos, ou seja, os 20 indivíduos amostrados não foram suficientes para representar a frequiência alélica de toda a População 1; b) devido ao fluxo gênico advindo de outras populações de $X$. brasiliensis.

A análise das freqüências alélicas é de grande importância, pois pode refletir melhor os eventos de deriva genética, perda ou fixação de alelos e seleção de genótipos, uma vez que os parâmetros utilizados no
Tabela 2. Freqüências alélicas e tamanho da amostra (n) em 16 locos aloenzimáticos para duas populações de Xylopia brasiliensis Sprengel.

Table 2. Alleles frequency and sample size (n) in 16 allozyme loci in two populations of Xylopia brasiliensis Sprengel.

\begin{tabular}{|c|c|c|c|c|}
\hline \multirow[b]{3}{*}{ Loco } & \multirow[b]{3}{*}{ Alelo } & \multicolumn{3}{|c|}{ Populações } \\
\hline & & \multirow{2}{*}{$\frac{1}{\text { Adultos }}$} & \multicolumn{2}{|c|}{2} \\
\hline & & & Jovens & Plântulas \\
\hline \multirow[t]{2}{*}{ Got-1 } & 1 & 1,000 & 1,000 & 1,000 \\
\hline & $\mathrm{n}$ & 19 & 19 & 20 \\
\hline \multirow[t]{2}{*}{ Got-2 } & 1 & 1,000 & 1,000 & 1,000 \\
\hline & $\mathrm{n}$ & 11 & 10 & 13 \\
\hline \multirow[t]{4}{*}{ Po-1 } & 1 & 1,000 & 0,292 & 0,632 \\
\hline & 2 & 0,000 & 0,417 & 0,105 \\
\hline & 3 & 0,000 & 0,292 & 0,263 \\
\hline & $\mathrm{n}$ & 8 & 12 & 19 \\
\hline \multirow[t]{4}{*}{ Po-2 } & 1 & 0,059 & 0,250 & 0,375 \\
\hline & 2 & 0,412 & 0,250 & 0,125 \\
\hline & 3 & 0,529 & 0,500 & 0,500 \\
\hline & $\mathrm{n}$ & 17 & 16 & 20 \\
\hline \multirow[t]{4}{*}{ Po-3 } & 1 & 0,925 & 0,900 & 0,800 \\
\hline & 2 & 0,000 & 0,025 & 0,025 \\
\hline & 3 & 0,075 & 0,075 & 0,175 \\
\hline & $\mathrm{n}$ & 20 & 20 & 20 \\
\hline \multirow[t]{4}{*}{ Acp-1 } & 1 & 0,250 & 0,200 & 0,425 \\
\hline & 2 & 0,550 & 0,500 & 0,350 \\
\hline & 3 & 0,200 & 0,300 & 0,225 \\
\hline & $\mathrm{n}$ & 20 & 20 & 20 \\
\hline \multirow[t]{4}{*}{ Acp-2 } & 1 & 0,000 & 0,000 & 0,375 \\
\hline & 2 & 0,000 & 0,125 & 0,125 \\
\hline & 3 & 1,000 & 0,875 & 0,500 \\
\hline & $\mathrm{n}$ & 10 & 12 & 20 \\
\hline \multirow[t]{3}{*}{$\beta$-Est-1 } & 1 & 0,200 & 0,300 & 0,425 \\
\hline & 2 & 0,800 & 0,700 & 0,575 \\
\hline & $\mathrm{n}$ & 20 & 20 & 20 \\
\hline \multirow[t]{3}{*}{$\beta$-Est- 2} & 1 & 0,583 & 0,472 & 0,176 \\
\hline & 2 & 0,417 & 0,528 & 0,824 \\
\hline & $\mathrm{n}$ & 6 & 18 & 17 \\
\hline \multirow[t]{3}{*}{$\beta$-Est-3 } & 1 & 0,286 & 0,781 & 0,577 \\
\hline & 2 & 0,714 & 0,219 & 0,423 \\
\hline & $\mathrm{n}$ & 7 & 16 & 13 \\
\hline \multirow[t]{3}{*}{ Gtdh-1 } & 1 & 0,708 & 0,885 & 0,579 \\
\hline & 2 & 0,292 & 0,115 & 0,421 \\
\hline & $\mathrm{n}$ & 12 & 13 & 19 \\
\hline \multirow[t]{3}{*}{ Gtdh-2 } & 1 & 0,571 & 0,929 & 0,700 \\
\hline & 2 & 0,429 & 0,071 & 0,300 \\
\hline & $\mathrm{n}$ & 14 & 14 & 20 \\
\hline \multirow[t]{5}{*}{ Pgi-1 } & 1 & 0,075 & 0,000 & 0,000 \\
\hline & 2 & 0,425 & 0,500 & 0,400 \\
\hline & 3 & 0,500 & 0,500 & 0,600 \\
\hline & $\mathrm{n}$ & 20 & 20 & 20 \\
\hline & & & & continuc \\
\hline
\end{tabular}


continuação

\begin{tabular}{|c|c|c|c|c|}
\hline \multirow[b]{3}{*}{ Loco } & \multirow[b]{3}{*}{ Alelo } & \multicolumn{3}{|c|}{ Populações } \\
\hline & & \multirow{2}{*}{$\frac{1}{\text { Adultos }}$} & \multicolumn{2}{|c|}{2} \\
\hline & & & Jovens & Plântulas \\
\hline \multirow[t]{3}{*}{ Mdh-1 } & 1 & 1,000 & 1,000 & 0,692 \\
\hline & 2 & 0,000 & 0,000 & 0,308 \\
\hline & $n$ & 15 & 13 & 13 \\
\hline \multirow[t]{3}{*}{ Mdh-2 } & 1 & 0,500 & 0,625 & 0,700 \\
\hline & 2 & 0,500 & 0,375 & 0,300 \\
\hline & $\mathrm{n}$ & 17 & 20 & 20 \\
\hline \multirow[t]{3}{*}{ Mdh-3 } & 1 & 0,775 & 0,861 & 0,700 \\
\hline & 2 & 0,225 & 0,139 & 0,300 \\
\hline & $\mathrm{n}$ & 20 & 18 & 20 \\
\hline Total & 36 & 30 & 33 & 35 \\
\hline
\end{tabular}

estudo de genética de populações não refletem diretamente frequiências alélicas eventualmente muito baixas.

Variabilidade genética intrapopulacional - A partir da análise das freqüências alélicas dos 16 locos isoenzimáticos foram estimados os índices de diversidade genética para as duas populações de $X$. brasiliensis (tabela 3). A porcentagem de locos polimórficos (P) foi de 68,8\% para a População 1 e 87,5\% para a População 2 , sendo $81,3 \%$ para os indivíduos jovens e $87,5 \%$ para as plântulas, evidenciando menor variabilidade dos indivíduos da População 1. Comparando-se a porcentagem de locos polimórficos obtida para $X$. brasiliensis com o valor de $77 \%$ encontrado para espécies comuns por Hamrick \& Loveless (1989) verifica-se que esta espécie apresentou elevado polimorfismo, o que torna estas populações favoráveis à conservação genética.

O número de alelos por loco foi de 1,9 para os indivíduos adultos, 2,1 para os jovens e 2,2 para as plântulas, próximos aos encontrados para várias espécies arbóreas (Oliveira et al. 2002, Sebben et al. 2003).

As heterozigosidades médias observadas $\left(\hat{H}_{o}\right)$ para a População 1, População 2 e seus estratos de indivíduos jovens e plântulas foram respectivamente 0,$457 ; 0,523$; 0,402 e 0,621 (tabela 3). As heterozigosidades médias esperadas $\left(\hat{H}_{e}\right)$ foram: 0,$313 ; 0,399 ; 0,329$ e 0,424 , respectivamente. A maior heterozigosidade observada na População 2 (indivíduos jovens e plântulas) pode ser explicada pelos alelos exclusivos observados nesta população na análise das freqüências alélicas.

Tabela 3. Índices de diversidade genética em duas populações de Xylopia brasiliensis Sprengel, baseados em 16 locos e sete sistemas enzimáticos. Valores entre colchetes referem-se aos intervalos de confiança e os valores entre parênteses, aos desvios padrões.

Table 3. Indexes of genetic diversity of two populations of Xylopia brasiliensis Sprengel, determined by 16 loci and seven isozymes systems. [ ] Confidence interval. ( ) Standard deviation.

\begin{tabular}{|c|c|c|c|c|}
\hline \multirow{3}{*}{ Índice de diversidade genética } & \multicolumn{4}{|c|}{ Populações } \\
\hline & \multirow{2}{*}{$\begin{array}{c}1 \\
\text { Adultos }\end{array}$} & \multirow{2}{*}{$\begin{array}{c}2 \\
\text { (sem estrato) } \\
\text { Jovens e plântulas }\end{array}$} & \multicolumn{2}{|c|}{$\begin{array}{c}2 \\
\text { (por estrato) }\end{array}$} \\
\hline & & & Jovens & Plântulas \\
\hline $\begin{array}{l}\text { Heterozigosidade média } \\
\text { observada }\left(\hat{H}_{o}\right)\end{array}$ & $0,457(0,096)$ & $0,523(0,071)$ & $0,402(0,084)$ & $0,621(0,078)$ \\
\hline $\begin{array}{l}\text { Heterozigosidade média } \\
\text { esperada }\left(\hat{H}_{e}\right)\end{array}$ & $0,313(0,061)$ & $0,399(0,049)$ & $0,329(0,059)$ & $0,424(0,048)$ \\
\hline $\begin{array}{l}\text { Porcentagem de locos } \\
\text { polimórficos }(0,95)\end{array}$ & 68,8 & 87,5 & 81,3 & 87,5 \\
\hline $\begin{array}{l}\text { Porcentagem de locos } \\
\text { polimórficos }(0,99)\end{array}$ & 68,8 & 87,5 & 81,3 & 87,5 \\
\hline Índice de fixação $(\hat{f})$ & $-0,491[-0,669$ a $-0,308]$ & $-0,316[-0,445 \mathrm{a}-0,192]$ & $-0,229[-0,452 a-0,011]$ & $-0,483[-0,582 \mathrm{a}-0,366]$ \\
\hline $\begin{array}{l}\text { Número médio de } \\
\text { alelos por locos (A) }\end{array}$ & $1,9(0,18)$ & $2,2(0,16)$ & $2,1(0,17)$ & $2,2(0,16)$ \\
\hline $\begin{array}{l}\text { Tamanho médio da } \\
\text { amostra por locos (n) }\end{array}$ & 14,8 & 34,7 & 16,3 & 18,4 \\
\hline
\end{tabular}


As populações estudadas apresentaram tendência ao excesso de heterozigotos em relação ao equilíbrio de Hardy-Weinberg (EHW), o que pode ser melhor visualizado pelos valores do índice de fixação $(\hat{f}):-0,491$ (População 1) e -0,316 (População 2), sendo observado, nos estratos desta última população valores de -0,229 para os indivíduos jovens e de -0,483 para as plântulas; indicando, a priori, ausência de endogamia para estas populações.

Estrutura genética-Os coeficientes de coancestralidade de Cockerham (1969) para as duas populações de $X$. brasiliensis encontram-se na tabela 4. As estimativas médias obtidas mostraram que houve ausência de endogamia para o conjunto das populações $(\hat{F}=-0,221)$ e tendência ao excesso de heterozigotos dentro das populações $(\hat{f}=-0,345)$, sugerindo que, em média, as populações não são endogâmicas.

A divergência genética entre populações foi alta $\left(\hat{\theta_{p}}=0,092\right)$. Isto significa que aproximadamente $9 \%$ da variabilidade genética se encontra entre as populações e que $91 \%$ desta variabilidade ocorre dentro das populações. A divergência encontrada neste trabalho (9\%) está de acordo com o observado em outras espécies arbóreas, ou seja, a maior proporção da

Tabela 4. Estimativas dos coeficientes médios de endogamia dentro das populações $(\hat{f})$, do conjunto das populações $(\hat{F})$ e da divergência genética entre populações $\left(\hat{\theta}_{p}\right)$ em duas populações de Xylopia brasiliensis Sprengel. Valores entre colchetes referem-se aos intervalos de confiança.

Table 4. Estimates of fixation index $(\hat{f})$, populations $(\hat{F})$ and genetic diversity $\left(\hat{\theta_{p}}\right)$ in two populations of Xylopia brasiliensis Sprengel. [ ] Confidence interval.

\begin{tabular}{lccc}
\hline Loco & $\hat{f}$ & $\hat{F}$ & $\hat{\theta_{p}}$ \\
\hline Po-1 & $-0,163$ & 0,130 & 0,252 \\
Po-2 & $-0,577$ & $-0,443$ & 0,085 \\
Po-3 & $-0,117$ & $-0,114$ & 0,003 \\
Acp-1 & $-0,114$ & $-0,112$ & 0,001 \\
Acp-2 & $-0,363$ & $-0,110$ & 0,185 \\
$\beta$-Est-1 & $-0,310$ & $-0,248$ & 0,047 \\
$\beta$-Est-2 & $-0,174$ & $-0,065$ & 0,092 \\
$\beta$-Est-3 & $-0,019$ & 0,234 & 0,248 \\
Gtdh-1 & $-0,400$ & $-0,424$ & $-0,017$ \\
Gtdh-2 & $-0,429$ & $-0,280$ & 0,104 \\
Pgi-1 & $-0,795$ & $-0,787$ & 0,004 \\
Mdh-1 & $-0,157$ & 0,035 & 0,105 \\
Mdh-2 & $-0,657$ & $-0,579$ & 0,047 \\
Mdh-3 & $-0,272$ & $-0,290$ & $-0,014$ \\
& $-0,345$ & $-0,221$ & 0,092 \\
Média & {$[-0,475 \mathrm{a}-0,217]$} & {$[-0,383 \mathrm{a}-0,064]$} & {$[0,039 \mathrm{a} 0,145]$} \\
& & &
\end{tabular}

variabilidade genética encontra-se dentro das populações $(91 \%)$.

A análise da estrutura genética, tomando a População 1 e os estratos da População 2 (tabela 5), apresentou altos valores de $\hat{\theta}_{p}$. A divergência genética entre os indivíduos adultos da População 1 e os jovens da População 2 foi de 0,129 e entre os adultos da População 1 e as plântulas foi de 0,121 . Estes valores tão próximos de divergência genética já eram esperados, visto que os dois estratos (indivíduos jovens e plântulas)

Tabela 5. Estimativas dos coeficientes médios de endogamia dentro das populações $(\hat{f})$, do conjunto das populações $(\hat{F})$ e da divergência genética entre populações $\left(\hat{\theta}_{p}\right)$, considerando a População 1 e os estratos de Xylopia brasiliensis Sprengel da População 2. Valores entre colchetes referem-se aos intervalos de confiança.

Table 5. Estimate of fixation index $(\hat{f})$, populations $(\hat{F})$ and genetic diversity $\left(\hat{\theta}_{p}\right)$ between Population 1 and Population 2 of Xylopia brasiliensis Sprengel. [ ] Confidence interval.

\begin{tabular}{lccc}
\hline Populações & $\hat{f}$ & $\hat{F}$ & $\hat{\theta}_{P}$ \\
\hline 1 e 2 (jovens) & $-0,330$ & $-0,158$ & 0,129 \\
{$[-0,520$ a $-0,139]$} & {$[0,078$ a $-0,418]$} & {$[0,016$ a 0,244$]$} \\
1 e 2 (plântulas) & $-0,475$ & $-0,296$ & 0,121 \\
{$[-0,570$ a $-0,373]$} & {$[-0,420$ a $-0,170]$} & {$[0,064$ a 0,184$]$}
\end{tabular}

ocupam a mesma área, estando igualmente sujeitos à incidência do fluxo gênico advindo da População 1.

A elevada divergência (9\%) e a proximidade (cerca de $100 \mathrm{~m}$ ) entre as populações analisadas indicaram que estas não possuem intenso fluxo gênico via pólen e/ou sementes, ou que este fluxo estaria encontrando barreiras favorecendo a entrada de material genético proveniente de outros fragmentos. A hipótese mais provável seria a de um fluxo gênico restrito entre as populações, visto que os fragmentos próximos aos locais amostrados não apresentam, com frequiência, indivíduos desta espécie.

Segundo Loveless \& Hamrick (1984), as espécies tipicamente alógamas apresentam alta variação genética dentro e pequena entre populações, no entanto, a divergência entre populações é reduzida de acordo com o aumento do fluxo gênico. Populações de espécies arbóreas, que possuem intenso movimento de pólen e sementes, apresentam menor diferenciação que aquelas com fluxo gênico restrito (Hamrick 1989).

Fluxo gênico $\left(\hat{N}_{m}\right)-$ As estimativas do fluxo gênico $\left(\hat{N}_{m}\right)$ e do tamanho de vizinhança $\left(\hat{N}_{b}\right)$ foram efetuadas 
Tabela 6. Fluxo gênico $\left(\hat{N}_{m}\right)$, estimativas indiretas da vizinhanças $\left(\hat{N}_{b}\right)$ obtido a partir de estimativas de divergências genética $\left(\hat{\theta}_{p}\right)$ das duas populações de Xylopia brasiliensis Sprengel. n: número de indivíduos analisados; np: número de populações analisadas.

Table 6. Gene flow $\left(\hat{N}_{m}\right)$, neighbouring size $\left(\hat{N}_{b}\right)$ obtained from estimated genetic diversity $\left(\hat{\theta}_{p}\right)$ in two populations of Xylopia brasiliensis Sprengel. (n) individuals number; (np) number of populations.

\begin{tabular}{lccccc}
\hline Populações & $\hat{N}_{m}$ & $\hat{N}_{b}$ & $\hat{\theta}_{p}$ & $\mathrm{n}$ & $\mathrm{np}$ \\
\hline 1 e 2 (jovens) & 0,42 & 2,64 & 0,129 & 40 & 2 \\
1 e 2 (plântulas) & 0,45 & 2,83 & 0,121 & 40 & 2 \\
1 e 2 & 0,62 & 3,90 & 0,092 & 60 & 2 \\
Média & 0,50 & 3,12 & & & \\
\hline
\end{tabular}

para as duas populações (tabela 6). Para a estimativa do fluxo gênico, utilizou-se o coeficiente de coancestralidade de Cockerham $\left(\hat{\theta_{p}}\right)$ como medida de diversidade genética entre populações, obtido a partir da análise de variância das freqüências alélicas, conforme sugerem Cockerham \& Weir (1993). O número médio de migrantes por geração $\left(\hat{N}_{m}\right)$ foi de 0,50 , indicando baixo fluxo gênico aparente, o valor de $\hat{N}_{b}$ foi em torno de 3 indivíduos. Segundo Slatkin \& Barton (1989), os valores de $\hat{N}_{m}$ e $\hat{N}_{b}$ determinam se a deriva genética, por si só, pode produzir variabilidade genética substancial entre locais. Se estes valores forem superiores a 1,0, então o fluxo gênico será alto o suficiente para prevenir diferenciação devido à deriva genética. Portanto, os valores obtidos neste estudo indicaram que o fluxo gênico não foi suficiente para prevenir uma diferenciação populacional devido à deriva genética, sendo considerado pequeno quando comparado com os valores obtidos para outras espécies arbóreas: $\hat{N}_{m}=0,79$ e $\hat{N}_{b}=4,96$ em Copaifera langsdorffii Desf. (Oliveira 2000); $\hat{N}_{m}=2,09$ e $\hat{N}_{b}=13$ em Macherium villosum Vog. (Giudice Neto 1999). O último autor ressalta, todavia, que as comparações entre as espécies não têm muito significado, a não ser demonstrar que algumas têm amplo fluxo de genes e outras não. Este raciocínio é válido para X. brasiliensis visto que, segundo Lorenzi (1992), a espécie produz anualmente pequenas quantidades de sementes viáveis e com baixa taxa de germinação, apresentando, portanto, fluxo gênico restrito.

As estimativas indiretas do tamanho de vizinhança $\left(\hat{N}_{b}\right)$ indicaram que o número de genitores que trocam alelos ao acaso está em torno de três indivíduos. Segundo Reis (1996), um número menor de indivíduos em uma mesma unidade de área implica em aumento da divergência entre as vizinhanças, em decorrência do aumento interno dos níveis de endogamia, alterando a estrutura genética da população a médio prazo.

Ao analisar o fluxo gênico $\left(\hat{N}_{m}\right)$ entre as Populações 1 e 2, observa-se que não houve diferença significativa, indicando que os indivíduos jovens e as plântulas sofreram a mesma incidência de fluxo gênico advindo da população de adultos, apesar deste ser de baixa amplitude. Esses valores estão coerentes, pois a divergência genética entre os indivíduos jovens e plântulas da População 2 e dos adultos da População 1 apresentou valores semelhantes.

Tamanho efetivo $\left(\hat{N}_{e}\right)$ - Um parâmetro muito importante nas atividades de preservação de germoplasma, coleta de sementes e conservação genética in situ é o tamanho efetivo $\left(\hat{N}_{e}\right)$, uma vez que ele trata da representatividade genética das amostras. As estimativas do tamanho efetivo populacional foram obtidas a partir do coeficiente de endogamia médio da população $(\hat{f})$ e do coeficiente de divergência genética entre populações $\left(\hat{\theta_{p}}\right)$ (tabela 7$)$. A partir da estimativa de $\hat{N}_{e}$ para as populações de $X$. brasiliensis pode-se afirmar que os 20 indivíduos (n) amostrados nas populações de adultos e nos estratos de indivíduos jovens e plântulas representaram, geneticamente 39,3, 25,9 e 38,7 plantas, respectivamente, de uma população panmítica ideal. Todas as populações apresentaram tamanho efetivo maior que o número de indivíduos amostrados, estando de acordo com os índices de fixação detectados, ou seja, ausência de endogamia nas populações estudadas. Os heterozigotos, por carregarem sempre dois alelos, representam um maior número de indivíduos na população e para as populações analisadas foi observada alta heterozigosidade.

As populações estudadas mostraram-se potenciais para a conservação genética in situ dada a heterozigosidade observada, principalmente, a População 1 por apresentar indivíduos reprodutivos.

Tabela 7. Tamanho efetivo $\left(\hat{N}_{e}\right)$ e número de indivíduos (n) das populações de Xylopia brasiliensis Sprengel.

Table 7. Effective size $\left(\hat{N}_{e}\right)$ and individuals number (n) in two populations of Xylopia brasiliensis Sprengel.

\begin{tabular}{lcc}
\hline População & $\hat{N}_{e}$ & $\mathrm{n}$ \\
\hline Adultos & 39,3 & 20 \\
Jovens & 25,9 & 20 \\
Plântulas & 38,7 & 20 \\
\hline
\end{tabular}


Para se obter a área mínima viável para a conservação genética in situ de indivíduos de X. brasiliensis da População 1, tomando-se como 50 o número mínimo de indivíduos (Frankel \& Soulé 1981)e sendo a relação $\hat{N}_{e} / \mathrm{n}$ da População 1 igual a 1,96 $(39,3 / 20)$ e o número médio de plantas por ha de 25,3 (dados não apresentados de levantamento florístico) supõe-se que esta poderá ser conservada dentro de uma área de 1,00 ha $[50 /(25,3 \times 1,96)]$, sem que ocorra o perigo da perda de alelos raros a curto prazo. No entanto, Frankel \& Soulé (1981) sugerem 500 ou mais indivíduos para a conservação de uma população ideal. Neste caso, a área necessária para a conservação genética in situ seria de 10,08 ha. Esta área relativamente pequena é devida à alta densidade de indivíduos nesta população. Como a área ocupada pela População 1 é de apenas 5,8 ha, é necessário a conservação de outras populações próximas, como a População 2, que permitam o fluxo gênico, embora restrito, mantendo-as geneticamente viáveis.

Agradecimentos - Ao CNPq pela bolsa de Iniciação Científica concedida ao primeiro autor e pela bolsa de Produtividade concedida ao segundo autor (Proc. n. 300542/89-5).

\section{Referências bibliográficas}

ALFENAS, A.C., PETERS, I., BRUNE, W. \& PASSADOR, G.C. 1991. Eletroforese de proteínas e isoenzimas de fungos e essências florestais. Editora UFV, Universidade Federal de Viçosa, Viçosa.

ALFENAS, A.C., BRUNE,W, OLIVEIRA, J.R., ALONSO, S.K. \& SCORTICHINI, M. 1998. Extração de proteínas para eletroforese. In Eletroforese de isoenzimas e proteínas afins; fundamentos em plantas e microrganismos (A.C. Alfenas, ed.). Editora UFV, Viçosa, p.85-114.

BRUNE, W., ALFENAS, A.C. \& JUNGHANS, T.G 1998. Identificações específicas de enzimas em géis. In Eletroforese de isoenzimas e proteínas afins; fundamentos em plantas e microrganismos (A.C. Alfenas, ed.). Editora UFV, Viçosa, p.201-328.

COCKERHAM, C.C. 1969. Variance of gene frequencies. Evolution 23:72-84.

COCKERHAM, C.C. \& WEIR, B.S. 1993. Estimation of Gene Flow From F-Statistics. Evolution 47:855-863.

CROW, J.F. \& AOKI, K. 1984. Group selection for polygenic behavioral trait: estimating the degree of population subdivision. Proceedings of the National Academy of Sciences of the United States of America 81:6073-6077.

CURI, N., LIMA, J.M., ANDRADE, H. \& GUALBERTO, V. 1990. Geomorfologia, física, química e mineralogia dos principais solos da região de Lavras (MG). Ciência e Prática 14:297-307.
FERREIRA, M.E. \& GRATTAPAGLIA, D. 1998. Introdução ao uso de marcadores moleculares em análise genética. $3^{\mathrm{a}}$ ed. Embrapa-Cenargen, Brasília.

FRANKEL, O.H. \& SOULÉ, M.E. 1981. Conservation and evolution. Cambridge University Press, Cambridge.

GIUDICE NETO, J.D. 1999. Estrutura genética por isoenzimas em populações naturais de Jacarandá Paulista (Macherium villosum Vog.). Dissertação de mestrado, Escola Superior de Agricultura "Luiz de Queiroz", Piracicaba.

HAMRICK, J.L. 1989. Isozymes and analysis of genetic structure in plant populations. In Isozymes and the analysis of genetic structure in plant populations. (D.E. Soltis \& P. Soltis, eds.). Chapman and Hall, New York, p.87-105.

HAMRICK, J.L. \& LOVELESS, M.D. 1989. The genetic structure of tropical tree populations: association with reproductive biology. In The evolutionary ecology of plants (J.H. Bock \& Y.B. Linhart, eds.). Westview Press, Boulder, p.129-146.

KEPHART, S.R. 1990. Starch gel electroforesis of plant isozyme: a comparative analysis of techniques. American Journal of Botany 77:693-712.

LEPSCH-CUNHA, N., KAGEYAMA, P.Y. \& VENCOVSKY, R. 1999. Genetic diversity of Couratari multiflora and Couratari guianensis (Lecythidaceae): consequences of two types of rarity in central Amazonia. Biodiversity and Conservation 8:1205-1218.

LEWIS, P.O. \& ZAYKIN, D. 2000. Genetic Data Analysis: Computer program for the analysis of allelic data. Version 1.0 (d15). http://alleyn.eeb.uconn.edu/gda/2000.

LORENZI, H. 1992. Árvores brasileiras: manual de identificação e cultivo de plantas arbóreas nativas do Brasil. Editora Plantarum, Nova Odessa.

LOVELESS, M.D. \& HAMRICK, J.L. 1984. Ecological determinants of genetic structure in plant populations. Annual Review of Ecology and Systematics 15:65-95.

OLIVEIRA, A.F. 2000. Estrutura genética de populações naturais de Copaifera langsdorffii Desf. a partir de isoenzimas. Dissertação de mestrado, Universidade Federal de Lavras, Lavras.

OLIVEIRA, A.F., CARVALHO, D. \& ROSADO, S.C.S. 2002. Taxa de cruzamento e sistema reprodutivo de uma população natural de Copaifera langsdorffii Desf. na região de Lavras (MG) por meio de isoenzimas. Revista Brasileira de Botânica 25:331-338.

REIS, M.S. 1996. Distribuição e dinâmica da variabilidade genética em populações naturais de palmiteiro (Euterpe edulis Martius). Tese de doutorado, Escola Superior de Agricultura "Luiz de Queiroz", Piracicaba.

ROBINSON, I.P. 1998. Aloenzimas na genética de populações de plantas. In Eletroforese de isoenzimas e proteínas afins; fundamentos em plantas e microrganismos (A.C. Alfenas, ed.). Editora UFV, Viçosa, p.329-380. 
SEBBEN, A.M., KAGEYAMA, P.Y. \& VENCOVSKY, R. 2003. Conservação genética in situ e número de matrizes para a coleta de sementes em população de Genipa americana L. Scientia Forestalis 63:13-22.

SLATKIN, M. \& BARTON, N.H. 1989. A comparison of three indirect methods for estimating averang levels of gene flow. Evolution 43:1349-1368.

SOLTIS, D.E. \& SOLTIS, P.S. 1989. Isozymes in plant biology. Dioscorides Press, Portland.
SWOFFORD, D.L. \& SELANDER, R.B. 1989. BIOSYS-1: A computer program for the analysis of allelic variation in population genetics and biochemical systematics. Release 1.7. Natural History Survey, Illinois.

VENCOVSKY, R. 1992. Análise de variância de frequiências alélicas. Revista Brasileira de Genética. 15:53-60.

WEEDEN, N.F. 1983. Evolution of plant isozyme. In Isozymes in plant genetics and breeding (S.D. Tanksley \& T.J. Orton, eds.). Elsevier Science, Amsterdam, p.175-205. 